\title{
Emissão e expansão foliar em três genótipos de tomateiro (Lycopersicon esculentum Mill.)
}

\author{
Leaf emergence and expansion in three tomato (Lycopersicon esculentum Mill.) genotypes
}

\author{
Carina Rejane Pivetta ${ }^{\mathrm{I}}$ Ivonete Fatima Tazzo $^{\mathrm{I}}$ Guilherme Fabiano Maass ${ }^{\mathrm{II}}$ \\ Nereu Augusto Streck ${ }^{\mathrm{II}}{ }^{*}$ Arno Bernardo Heldwein ${ }^{\mathrm{III}}$
}

\section{RESUMO}

O objetivo deste trabalho foi estimar o filocrono na haste principal e em hastes laterais de primeira ordem $e$ estimar a área foliar a partir do número de folhas em três genótipos de tomateiro cultivados em estufa plástica. Um experimento foi conduzido em estufa plástica na área experimental do Departamento de Fitotecnia da Universidade Federal de Santa Maria, Santa Maria, RS. Foram utilizados três genótipos de tomate: “Kátia”, "Durino” e "Emperor”. O transplante das mudas com 3-4 folhas definitivas foi realizado em 31/10/2005. O delineamento experimental foi o de blocos ao acaso com quatro repetições, compostas de duas fileiras de oito plantas. Em seis plantas de cada repetição foram realizadas observações do número de folhas na haste principal e em hastes laterais de primeira ordem e em duas plantas de cada repetição foram medidos o comprimento e a largura das folhas na haste principal. O filocrono foi estimado pelo inverso do coeficiente angular da regressão linear entre o número de folhas acumuladas na haste e a soma térmica acumulada após o transplante. O filocrono da haste principal foi menor do que o filocrono das hastes laterais de primeira ordem. A área foliar do tomateiro em uma haste pode ser estimada através do número de folhas acumuladas nesta haste.

Palavras-chave: aparecimento de folhas, soma térmica, desenvolvimento vegetal, área foliar, modelagem.

\section{ABSTRACT}

This study was aimed at estimating the phyllochron on the main stem and on first order lateral branches, and estimate leaf area from leaf number in three tomato genotypes grown inside a plastic green-house. An experiment was conducted inside a plastic greenhouse at the experimental area of the Plant Science Department of the Federal University of Santa Maria, Santa Maria, RS, Brazil. Three tomato genotypes were used: 'Kátia', 'Durino', and 'Emperor'. Three to fourleaf seedlings were transplanted on 10/31/2005. The experimental design was a complete randomized block with four replications composed of two 8-plants rows. The number of leaves on the main stem and on first order lateral branches was counted in six plants of each replication. Leaf length and width were measured on two plants per replication. The phyllochron was estimated as the inverse of the slope of the linear regression of leaf number against accumulated thermal time from transplanting. The phyllochron on the main stem was greater than on the first order lateral branches. Leaf area on a stem of the tomato plant can be estimated from the number of accumulated lateral leaves on this stem.

Key words: leaf appearance, thermal time, plant development, leaf area, modeling.

\section{INTRODUÇÃO}

O tomate (Lycopersicon esculentum Mill.) é a mais importante hortaliça produzida no Brasil, sendo consumida na dieta alimentar como fonte de vitaminas e minerais. Sua produção mundial é estimada em cerca de 110 milhões de toneladas (FAO, 2003). Por sua importância econômica, o tomateiro tem sido uma das espécies mais cultivadas em ambiente protegido, um sistema de cultivo de grande relevância social por ser praticado geralmente em pequenas propriedades $\mathrm{e}$

'Programa de Pós-graduação em Agronomia, Universidade Federal de Santa Maria (UFSM), Santa Maria, RS, Brasil.

IICurso de Graduação em Agronomia, UFSM, Santa Maria, RS, Brasil.

IIIDepartamento de Fitotecnia, Centro de Ciências Rurais (CCR), UFSM, Avenida Roraima, 1000, Camobi, 97105-900, Santa

Maria, RS. E-mail: nstreck1@smail.ufsm.br. *Autor para correspondência. 
utilizar mão-de-obra familiar (RADIN, 2002). O cultivo em ambiente protegido permite que este seja realizado durante a maioria dos meses do ano, diminuindo dessa forma a sazonalidade de produção, principalmente na região Sul do Brasil, onde ocorrem baixas temperaturas do ar durante o inverno, que limitam o crescimento e desenvolvimento do tomateiro a céu aberto.

O desenvolvimento e o crescimento vegetais são processos independentes e sincronizados que podem ocorrer simultaneamente ou não (WILHELM \& McMASTER, 1995). Desenvolvimento refere-se à diferenciação celular, à iniciação e ao aparecimento de órgãos e se estende até a senescência da cultura, enquanto crescimento é o aumento irreversível de uma grandeza física como massa, área, altura, diâmetro e volume(HODGES, 1991). Como exemplo de parâmetros de desenvolvimento, tem-se a velocidade ou taxa de aparecimento de folhas (TAF), enquanto expansão foliar é um exemplo de parâmetro de crescimento. Integrando-se a TAF no tempo tem-se o número de folhas acumuladas na haste principal (NF), o qual é uma excelente medida de desenvolvimento vegetal (STRECK, 2002; STRECK et al., 2003; XUE, et al., 2004). O NF está relacionado com o surgimento de outros órgãos na planta em várias espécies, como perfilhos em gramíneas (KLEPPER et al., 1982), ramificações laterais em batata (VOS \& BIEMOND, 1992), flores femininas e masculinas em melão (STRECK et al., 2005a), diferenciação da espiga em trigo (STRECK et al., 2003) e milho (FORSTHOFER et al., 2004) e inflorescências em tomate (MEIER, 2001). O NF também está relacionado com a expansão da área foliar, a qual está relacionada com a interceptação de radiação solar, a fotossíntese e o acúmulo de fitomassa (SINCLAIR et al., 2004; STRECK et al., 2005b; DELLAI et al., 2005). Por isso, o cálculo da taxa de aparecimento de folhas, do NF e da área foliar são parte de muitos modelos de simulação do crescimento e rendimento das culturas agrícolas (WEIR et al., 1984; RITCHIE, 1991; STRECK et al., 2003).

Uma das maneiras freqüentemente usadas para calcular o NF nos modelos matemáticos é através do conceito do filocrono, definido como o intervalo de tempo entre o aparecimento de duas folhas sucessivas na haste principal (WILHELM \& McMASTER, 1995; XUE et al., 2004; STRECK et al., 2005b). A unidade de tempo mais usada para o filocrono é a soma térmica, com unidade ${ }^{\circ} \mathrm{C}$ dia, a qual tem maior significado biológico em plantas do que dias do calendário civil, pois leva em conta o efeito da temperatura sobre o desenvolvimento vegetal (GILMORE \& ROGERS, 1958; RUSSELE et al., 1984; McMASTER \& SMIKA, 1988). A unidade do filocrono é, portanto, ${ }^{\circ} \mathrm{C}$ dia folha ${ }^{-1}$.
Trabalhos de pesquisa utilizando o conceito de filocrono foram realizados para diversas culturas agrícolas, como cevada e trigo (KIRBY, 1995; XUE et al., 2004), gramíneas forrageiras (FRANK \& BAUER, 1995; MOORE \& MOSER, 1995; ALMEIDAet al., 1997), alface (HERMES et al., 2001; DUARTE et al., 2005), arroz (NEMOTO et al., 1995; WALTER et al., 2005), batata (DELLAI et al., 2005), lírio (STRECK et al., 2004 ; SCHUH et al., 2005), meloeiro (STRECK et al., 2005a) e cártamo (STRECK et al., 2005b). Com relação ao tomateiro, estudos sobre emissão de folhas são escassos. No trabalho de SCHOLBERG et al. (2000), a taxa de emissão de nós média em um genótipo de tomateiro foi de 0,49 nós dia ${ }^{-1}$ e a emissão de nós cessou após o acumulo de $530^{\circ} \mathrm{C}$ dia, com número final de nós na haste principal de 19 a 21 nós.

Em espécies como trigo, cevada, forrageiras e arroz, tem sido relatado que o filocrono é diferente para diferentes genótipos da mesma espécie (FRANK \& BAUER, 1995; WALTER et al., 2005). O escasso número de trabalhos realizados com tomateiro e o fato de existirem diferentes genótipos de tomateiro disponíveis no mercado, que são conduzidos de diferentes maneiras (poda lateral deixando-se uma haste ou duas por planta até crescimento sem poda), constituíram o incentivo para este esforço científico.

O objetivo deste trabalho foi estimar o filocrono na haste principal e em hastes laterais de primeira ordem e estimar a área foliar a partir do número de folhas em três genótipos de tomateiro cultivados em estufa plástica.

\section{MATERIAL E MÉTODOS}

O experimento foi realizado em uma estufa tipo arco-pampeana com dimensões de 24 x 10m, coberta com polietileno de baixa densidade (PEBD), instalada na área experimental do Departamento de Fitotecnia da Universidade Federal de Santa Maria, Santa Maria, RS (Latitude: 2943'S, longitude: 5343'W e altitude: 95m). Foram usados três genótipos de tomate distintos quanto ao hábito de crescimento: "Kátia” (tipo industrial, de hábito de crescimento determinado), "Emperor” (tipo salada, de hábito de crescimento determinado) e "Durino” (tipo cereja, de hábito de crescimento indeterminado). A semeadura foi realizada em bandejas com substrato comercial Plantimax ${ }^{\circledR}$ e o transplante para a estufa foi realizado em 31/10/2005, quando as plantas possuíam 3 a 4 folhas definitivas. As plantas foram cultivadas no solo em camalhão coberto com plástico opaco preto, no espaçamento de 0,3 x 1,0 m. A irrigação foi realizada por gotejamento, e a adubação foi feita segundo a recomendação da COMISSÃO DE FERTILIDADE DO SOLODORS E SC (2004). 
O delineamento experimental foi blocos ao acaso, com quatro repetições. Cada repetição era composta de duas fileiras de oito plantas. As plantas foram conduzidas deixando-se três inflorescências na haste principal (HP) e quatro hastes laterais de primeira ordem (HL), sendo duas entre a 1a e a 2 a inflorescência e duas entre a $2^{\underline{a}}$ e a $3^{\mathrm{a}}$ inflorescência (Figura 1). A opção de deixar apenas três inflorescências na HP deveu-se ao fato de que os genótipos de hábito determinado não emitiram folhas após a $3^{\text {a }}$ inflorescência na HP.

O manejo da cultura constituiu-se da aplicação de defensivos químicos contra patógenos e pragas e da desbrota das ramificações laterais que não fizeram parte do experimento (Figura 1). Seis plantas de cada repetição, três em cada linha, foram marcadas com arames coloridos após o transplante. Nestas plantas, foram realizadas a contagem do número de folhas visíveis na HP e HL duas vezes por semana. Uma folha foi considerada visível quando apresentava pelo menos $1 \mathrm{~cm}$ de comprimento. Semanalmente foram realizadas medidas do comprimento (C) e maior largura (L) de todas as folhas verdes da HP em duas das plantas marcadas por parcela. Com estes dados, foi calculada a área das folhas individuais (AF) por $\mathrm{AF}=0,3676 * \mathrm{C} * \mathrm{~L}(\mathrm{RIGHI}$, 2000).

As temperaturas mínima e máxima diárias do ar durante o experimento foram medidas por um termômetro de mínima de álcool e um termômetro de máxima de mercúrio, respectivamente, no interior de um abrigo meteorológico a $1,5 \mathrm{~m}$ de altura do solo no centro da estufa. A temperatura média diária do ar

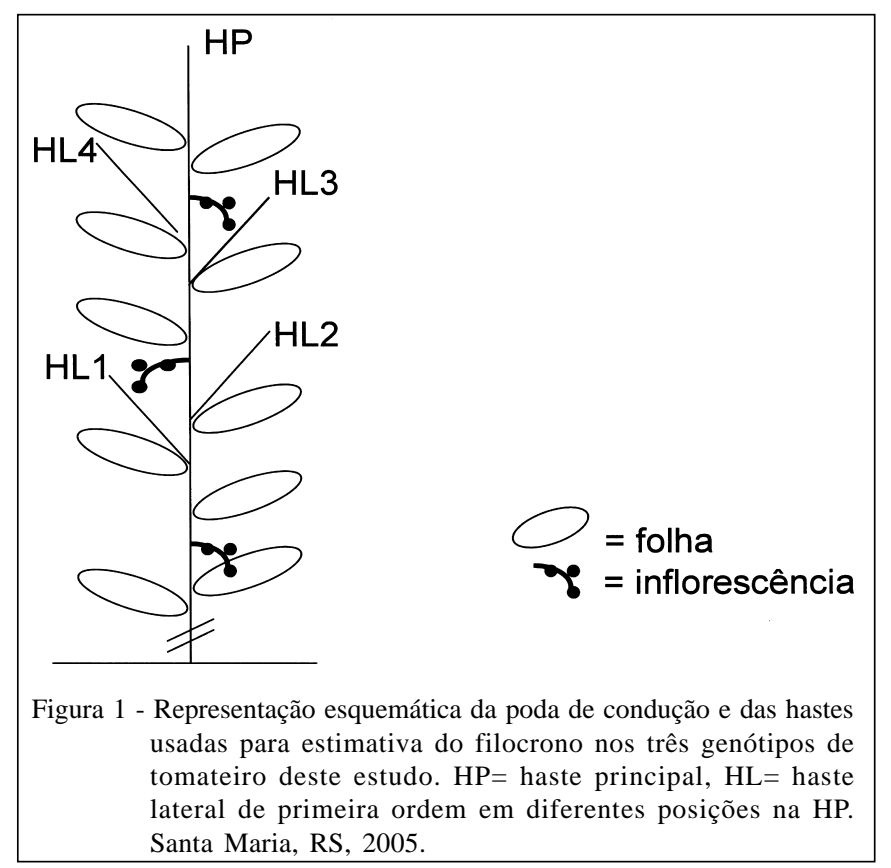

(Tmédia) foi calculada pela média aritmética entre a mínima e a máxima diárias.

Os graus-dia diários (GDD, ${ }^{\circ} \mathrm{C}$ dia) foram calculados por (GILMORE \& ROGERS, 1958, ARNOLD, 1960; STRECK et al., 2005a):

$\mathrm{GDD}=\left(\mathrm{T}_{\text {média }}-\mathrm{T}_{\mathrm{b}}\right) * 1$ dia, quando $\mathrm{T}_{\mathrm{b}}<\mathrm{T}_{\text {média }} \leq \mathrm{T}_{\text {ot }}$ e (1) e $\mathrm{GDD}=\left[\left(\mathrm{T}_{\mathrm{ot}}-\mathrm{T}_{\mathrm{b}}\right) *\left(\mathrm{~T}_{\text {média }}-\mathrm{T}_{\max }\right)\right] /\left(\mathrm{T}_{\mathrm{ot}}-\mathrm{T}_{\max }\right) * 1$ dia, quando $\mathrm{T}_{\mathrm{ot}}<\mathrm{T}_{\text {média }} \leq \mathrm{T}_{\text {max }}$ em que $\mathrm{T}_{\mathrm{b}}, \mathrm{T}_{\text {ot }} \mathrm{e}^{\mathrm{m}} \mathrm{T}_{\text {max }}^{\text {max }}$ são as temperaturas cardinais (base, ótima e máxima, respectivamente) de emissão de folhas. Foram assumidos $\mathrm{T}_{\mathrm{b}}=10^{\circ} \mathrm{C}, \mathrm{T}_{\mathrm{ot}}=22^{\circ} \mathrm{C} \mathrm{e} \mathrm{Tmax}=$ $34^{\circ} \mathrm{C}$ (SILVA et al., 2000). A soma térmica acumulada (STa, ${ }^{\circ} \mathrm{C}$ dia) a partir do transplante foi calculada acumulando-se GDD, ou seja STa= (GDD.

Em cada repetição (média de 6 plantas), foi realizada uma análise de regressão linear simples entre o número de folhas acumuladas (NF) na haste principal e nas hastes secundárias e a STa. O filocrono da haste principal e das hastes secundárias para cada genótipo foi estimado pelo inverso do coeficiente angular da regressão linear simples entre NF e STa até a 12a folha (KLEPPER et al., 1982; XUE et al., 2004; STRECK et al., 2005b). Os dados de filocrono foram submetidos à análise de variância e as médias dos genótipos foram distinguidas pelo teste Tukey em nível de 5\% de probabilidade de erro, utilizando-se o software estatístico SAS (SAS Institute, 1997). Na análise estatística da variável filocrono considerou-se um experimento bifatorial (3 genótipos x 2 hastes) para estudar o efeito da HP e HL sobre esta variável. Ajustou-se também o modelo não linear $\mathrm{Y}=\mathrm{a}^{*} \mathrm{e}^{\left(\mathrm{b}^{* \mathrm{x}}\right)}$ aos dados AF acumulada (Y) e NF (X) na HP utilizando-se os dados individuais das oito plantas por parcela (SINCLAIR et al., 2004).

\section{RESULTADOS E DISCUSSÃO}

Durante o período experimental, a temperatura média do ar foi de $25,9^{\circ} \mathrm{C}$, com valores absolutos de temperatura mínima e máxima de $8,7^{\circ} \mathrm{C}$ e $43,8^{\circ} \mathrm{C}$, respectivamente. A temperatura média do ar esteve praticamente todo o período experimental acima da temperatura ótima e abaixo da temperatura máxima para o desenvolvimento do tomateiro, com exceção de sete dias no início do experimento.

O número de folhas na HP foi maior até a $1^{\underline{a}}$ inflorescência do que entre a $1^{\underline{a}}$ e a $2^{\underline{a}}$ e entre a $2^{\underline{a}}$ e a $3^{3}$ inflorescência (Tabela 1$)$. O genótipo “Durino” (indeterminado) teve significativamente menos folhas até a $1^{\text {a }}$ inflorescência (6,3 folhas) do que os outros 
Tabela 1 - Número final de folhas (NFF) até a $1^{\mathrm{a}}$ inflorescência ( $1^{\mathrm{a}}$ inf.), entre a $1^{\mathrm{a}}$ e a $2^{\mathrm{a}}$ inflorescência ( $1^{\mathrm{a}}$ a $2^{\mathrm{a}}$ inf.) e entre a $2^{\mathrm{a}}$ e a $3^{\mathrm{a}}$ inflorescência ( $2^{\mathrm{a}}$ a $3^{\mathrm{a}}$ inf.) e filocrono da haste principal de três genótipos de tomateiro cultivado em estufa plástica. Santa Maria,RS, 2005.

\begin{tabular}{lcccc}
\hline & \multicolumn{3}{c}{ NFF (folhas planta $\left.{ }^{-1}\right)$} \\
\cline { 2 - 4 } Genótipo & $1^{\mathrm{a}}$ inf. & $1^{\mathrm{a}} \mathrm{a} 2^{\mathrm{a}}$ inf. & $2^{\mathrm{a}}$ a $3^{\mathrm{a}}$ inf. & Filocrono $\left({ }^{\circ} \mathrm{C}\right.$ dia folha $\left.{ }^{-1}\right)$ \\
\hline Emperor & $8,9 \mathrm{Aa}$ & $1,8 \mathrm{Bc}$ & $1,3 \mathrm{Bb}$ & $16,9 \mathrm{a}$ \\
Kátia & $9,6 \mathrm{Aa}$ & $3,0 \mathrm{Bb}$ & $3,0 \mathrm{Ba}$ & $15,8 \mathrm{ab}$ \\
Durino & $6,3 \mathrm{Ab}$ & $4,1 \mathrm{Ba}$ & $3,3 \mathrm{Ba}$ & $14,2 \mathrm{~b}$ \\
\hline
\end{tabular}

Médias seguidas pela mesma letra minúscula na vertical e maiúscula na horizontal não diferem entre si pelo Teste de Tukey a 5\% de probabilidade de erro.

dois genótipos (determinados), os quais não diferiram entre si (8,9 e 9,3 folhas), e mais folhas entre a $1^{\text {a }}$ e a $2^{\text {a }}$ inflorescência (4,1 folhas) do que os outros dois genótipos, e número de folhas (3,3 folhas) entre a $2^{\mathrm{a}} \mathrm{e}$ a $3^{\text {a }}$ inflorescência similar ao genótipo "Kátia" (determinado) e maior que "Emperor” (determinado).

A relação entre o número de folhas acumuladas na HP e HL e a soma térmica acumulada foi linear para os três genótipos, com elevados valores de coeficientes de determinação $\left(r^{2}>0,92\right)$. Essa relação indica que a temperatura média do ar foi o fator ecológico que determinou a emissão de folhas em tomateiro, fato que também foi verificado por STRECK et al. (2004), STRECK et al. (2005b) e DELLAI et al. (2005) para as culturas de lírio, cártamo e batata, respectivamente. Pela análise de variância para a variável filocrono, pôde-se observar efeito significativo dos fatores genótipos e hastes (haste principal e hastes laterais) e da interação genótipo $\mathrm{x}$ haste. O filocrono da HP foi estatisticamente menor do que o filocrono das hastes laterais nos três genótipos, o que indica redução na velocidade de emissão de folhas nas hastes laterais do tomateiro.

Os maiores valores de filocrono na HP foram dos genótipos “Emperor” e "Kátia”, que não diferiram estatisticamente entre si. O filocrono do genótipo "Durino" foi o menor e não diferiu do "Emperor” (Tabela 1). Portanto, o genótipo “Durino”, de hábito indeterminado e frutos do tipo cereja, possui uma taxa de aparecimento de folhas superior à do "Emperor”. A data de abertura da 1a flor é variável entre os genótipos e dependente do número final de folhas (NFF) emitidas até $\mathrm{o}$ aparecimento da $1^{\mathrm{a}}$ inflorescência. $\mathrm{O}$ menor NFF até a $1^{\mathrm{a}}$ inflorescência e o menor filocrono do genótipo "Durino" (Tabela 1) conferem a este genótipo maior precocidade em relação aos outros dois genótipos.

A maior diferença de filocrono na HP entre as cultivares ("Durino" $\mathrm{x}$ "Emperor") foi de $2,7^{\circ} \mathrm{C}$ dia folha ${ }^{-1}$. Levando-se em consideração que o genótipo “Durino" emitiu a 1ª inflorescência em média com seis folhas e a "Emperor" com 9 folhas, se for utilizado um único valor de filocrono $\left(14,2^{\circ} \mathrm{C}\right.$ dia folha $\left.{ }^{-1}\right)$ para os dois genótipos para estimar-se a data de emissão da $1^{\text {a }}$ inflorescência baseado no filocrono, isso resultará em um erro de $16,2^{\circ} \mathrm{C}$ dia e de $24,4^{\circ} \mathrm{C}$ dia, respectivamente (Tabela 1). A implicação destes resultados é que, se durante o período de emissão de folhas as temperaturas permanecerem próximas da ótima para a cultura, o erro da estimativa será de apenas 1 a 2 dias do calendário civil. No entanto, em períodos em que a temperatura do ar é abaixo da temperatura ótima, o que frequentemente ocorre durante os meses de outono e inverno dentro das estufas no Rio Grande do Sul, esse erro será maior. Nas hastes laterais de primeira ordem, o genótipo "Durino" (indeterminado) possui o menor filocrono médio das quatro hastes $\left(22,6^{\circ} \mathrm{C}\right.$ dia folha ${ }^{-1}$, Tabela 2), mantendo a mesma tendência de menor filocrono observado na haste principal deste genótipo (Tabela 1). O genótipo “Emperor” teve o maior filocrono médio $\left(50,7^{\circ} \mathrm{C}\right.$ dia) nas hastes laterais (Tabela 2$)$, seguindo a mesma tendência observada na haste principal para este genótipo (Tabela 1).

Considerando-se a média dos três genótipos, não houve diferença de filocrono nas hastes laterais em posições diferentes na HP (Tabela 2). Entre os genótipos, "Durino" seguiu a tendência da média, ou seja, sem diferença estatística entre HL, "Emperor” teve filocrono estatisticamente menor na HL3 e "Kátia” teve menor filocrono em HL2 e HL4, as quais não diferiram entre si (Tabela 2). Para o genótipo “Emperor”, deve-se ressaltar que plantas de apenas uma repetição emitiram HL3, o que pode ter afetado e ocasionado diminuição do filocrono dessa haste.

Com relação ao filocrono das hastes laterais do genótipo "Kátia”, verificou-se que as hastes HL1 e HL3 possuem maiores valores de filocrono e, portanto, menor taxa de aparecimento de folhas, se comparadas com as hastes HL2 e HL4, com menores valores de filocrono (Tabela 2). As hastes laterais HL2 e HL4 
Tabela 2 - Filocrono das hastes laterais de primeira ordem em três genótipos de tomateiro cultivado em estufa plástica. Santa Maria, RS, 2005.

\begin{tabular}{|c|c|c|c|c|c|}
\hline Genótipo & HL1* & HL2* & HL3* & HL4* & Média \\
\hline Emperor & 49,8Аa & 53,4Aa & 25,9Ba & 70,0Aа & $50,7 a$ \\
\hline Kátia & 32,7Ac & $22,2 \mathrm{Bb}$ & 31,4Aa & $20,6 \mathrm{Bb}$ & $26,8 b$ \\
\hline Durino & $21,6 \mathrm{Ab}$ & $24,4 \mathrm{Ab}$ & $22,8 \mathrm{Aa}$ & $21,6 \mathrm{Ab}$ & $22,6 b$ \\
\hline Média & $33,4 \mathrm{~A}$ & $31,5 \mathrm{~A}$ & $27,0 \mathrm{~A}$ & $26,6 \mathrm{~A}$ & \\
\hline
\end{tabular}

*Hastes laterais de primeira ordem são identificadas acropetalmente conforme a Figura 1. Médias seguidas por mesmas letras maiúsculas na horizontal e minúsculas na vertical não diferem entre si pelo teste de Tukey a 5\% de probabilidade de erro.

estavam localizadas logo abaixo das inflorescências (Figura 1), as quais funcionam como um dreno mais forte de fotoassimilados da planta (ANDRIOLO, 1999), enquanto que HL1 e HL3 estavam em um nó abaixo e, portanto, mais afastadas da inflorescência (Figura 1). Observou-se crescimento mais rápido das hastes HL2 e HL4 em relação ao crescimento de HL1 e HL3. O crescimento mais vigoroso e a maior velocidade de emissão de folhas nas hastes que estão localizadas logo abaixo das inflorescências (HL2 e HL4) certamente constituem estratégias da planta de tomateiro para maximizar a translocação de fotoassimilados para crescimento dos frutos. Os frutos são importantes órgãos de reserva da planta de tomateiro para crescimento das sementes, órgãos de propagação desta espécie. Sob o ponto de vista econômico, os frutos constituem a parte de interesse comercial desta espécie.

A área foliar é um parâmetro de crescimento em modelos de simulação do crescimento e rendimento das culturas (WEIR et al., 1984; RITCHIE et al., 1991). Uma das maneiras mecanísticas de simular a evolução da área foliar da planta é através do NF (SINCLAIR et al., 2004). Nesta metodologia, assume-se que a folha aparece e depois se expande, o que é realístico do ponto de vista da planta. O NF pode ser facilmente estimado pelo filocrono. Portanto, obtiveram-se modelos nãolineares para a área foliar (AF) acumulada e o número de folhas acumuladas (NF) na HP para os três genótipos de tomateiro usados neste estudo (Figura 2).

Para os genótipos "Durino”, de hábito de crescimento indeterminado, e "Kátia”, de hábito de crescimento determinado, foi possível o ajuste de uma única equação, indicando similaridade na evolução da área foliar nestes dois genótipos (Figura 2a). A equação ajustada para estes dois genótipos foi $\mathrm{AF}=9,1094 \mathrm{e}^{0,4272 \mathrm{NF}}$. Já para o genótipo "Emperor”, o qual é de hábito de crescimento determinado e produziu menos folhas e folhas maiores na HP, obteve-se o modelo AF=4,9985e $\mathrm{e}^{0,5717 \mathrm{NF}}$ (Figura 2b). Diferenças genotípicas na evolução da área foliar com o NF foram relatadas para cana-de-açúcar por SINCLAIR et al. (2004) e estão associadas à morfologia da folha. Os resultados deste estudo indicam uma alternativa atrativa para estimar a AF do tomateiro a partir do NF, já que esta metodologia tem como vantagem a facilidade de contagem do NF quando comparada com

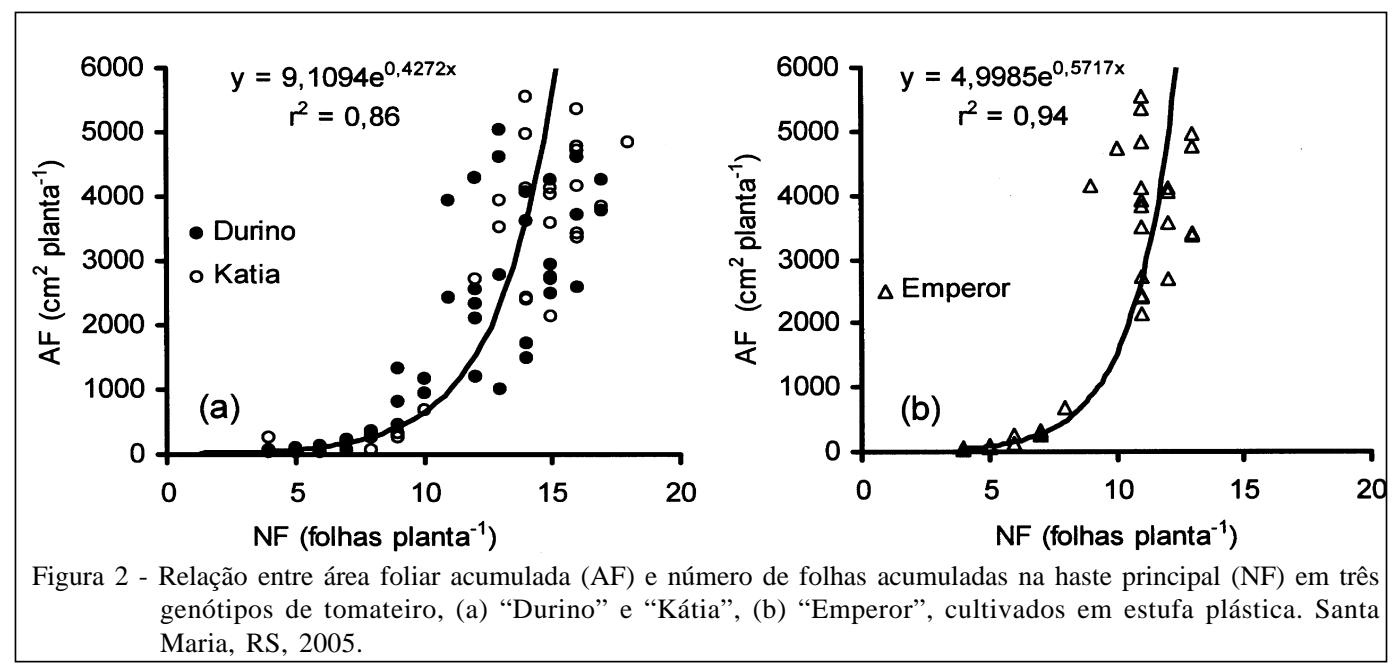

Ciência Rural, v.37, n.5, set-out, 2007. 
a metodologia de medida do comprimento e largura das folhas na planta de tomateiro, como é freqüentemente realizado (RIGHI, 2000), a qual exige muita mão-de-obra e tempo. Uma possibilidade também atrativa é utilizar os mesmos coeficientes do modelo para mais de um genótipo, como foi o caso dos genótipos “Durino” e “Kátia” (Figura 2a), pois, como existem muitos genótipos de tomateiro disponíveis no mercado, relações matemáticas gerais diminuem a mão-de-obra e o tempo para calibrar os coeficientes, e assim tornam o modelo de mais fácil aplicação (STRECK, 2002).

\section{CONCLUSÃO}

A emissão de folhas em tomateiro é mais rápida na haste principal do que nas hastes laterais de primeira ordem e pode ser descrita pela soma térmica. A área foliar em uma haste de tomateiro pode ser estimada através do número de folhas acumuladas nesta haste.

\section{AGRADECIMENTOS}

C. R. Pivetta agradece à Fundação Coordenação de Aperfeiçoamento de Pessoal de Nível Superior (CAPES) pela bolsa de mestrado; I. F. Tazzo agradece ao Conselho Nacional de Desenvolvimento Científico e Tecnológico (CNPq) pela bolsa de Doutorado; G. F. Maass agradece ao CNPq pela bolsa de iniciação científica e A.B. Heldwein e N. A. Streck agradecem ao $\mathrm{CNPq}$ pela bolsa de Produtividade em Pesquisa.

\section{REFERÊNCIAS}

ALMEIDA, E.X. et al. Oferta de forragem e variáveis morfogênicas em capim-elefante anão cv. Mott. In: REUNIÃO ANUAL DA SOCIEDADE BRASILEIRA DE ZOOTECNIA, 34., 1997, Juiz de Fora. Anais... Juiz de Fora: Sociedade Brasileira de Zootecnia, 1997. p.240-242.

ANDRIOLO, J.L. Fisiologia das culturas protegidas. Santa Maria: UFSM, 1999. 142p.

ARNOLD, C.Y. Maximum-minimum temperature as a basis for computing heat units. Proceedings of the American Society for Horticulture Science, v.76, n.1, p.682-692, 1960 .

COMISSÃO DE FERTILIDADE DO SOLO DO RS E SC. Recomendação de adubação e calagem para os estados do Rio Grande do Sul e Santa Catarina. Passo Fundo: SBCS/EMBRAPA-CNPT, 2004. 394p.

DELLAI, J. et al. Filocrono em diferentes densidades de plantas de batata. Ciência Rural, v.35, n.6, p.1269-1274, 2005.

DUARTE, G.B. et al. Análise de emissão de folhas e diâmetro de plantas de alface com base na temperatura do ar em cultivo protegido com adubação orgânica. In: CONGRESSO
BRASILEIRO DE AGROMETEOROLOGIA, 14., 2005, Campinas, SP. Anais... Campinas: Sociedade Brasileira de Agrometeorologia, 2005. 173p. p.15.

FAO[Food and Agriculture Organization]. Anuario de Producción 2003. Capturado em 25 nov. 2005. Online. Disponível na Internet http://www.fao.org/catalog/bollettin.

FORSTHOFER, E.L. et al. Desenvolvimento fenológico e agronômico de três híbridos de milho em três épocas de semeadura. Ciência Rural, v.34, n.5, p.1341-1348, 2004.

FRANK, A.B.; BAUER, A. Phyllochron differences in wheat, barley and forage grasses. Crop Science, v.35, n.1, p.19-23, 1995.

GILMORE, E.C. Jr.; ROGERS, J.S. Heat units as a method of measuring maturity in corn. Agronomy Journal, v.50, n.10, p.611-615, 1958.

HERMES, C.C. et al. Emissão de folhas de alface em função da soma térmica. Revista Brasileira de Agrometeorologia, v.9, n.2, p.269-275, 2001.

HODGES, T.F. Predicting crop phenology. Boca Raton: CRC, 1991. 233p.

KIRBY, E.J.M. Factors affecting rate of leaf appearance in barley and wheat. Crop Science, v.35, n.1, p.11-18, 1995.

KLEPPER, B. et al. Quantitative characterization of vegetative development in small cereal grains. Agronomy Journal, v.74, p.789-792, 1982.

McMASTER, G.S.; SMIKA, D.E. Estimation and evaluation of winter wheat phenology in the central Great Plains. Agricultural and Forest Meteorology, v.43, n.1, p.1-18, 1988.

MEIER, U. Growth stages of mono-and dicotyledonous plants. Berlin: Federal Biological Research Centre for Agriulture an Forestry, 2001. 158p. (BBCH Monograph).

MOORE, K.J.; MOSER, L.E. Quantifying developmental morphology of perennial grasses. Crop Science, v.35, n.1, p.37-43, 1995.

NEMOTO, K. et al. Shoot and root development in rice related to the phyllochron. Crop Science, v.35, n.1, p.24-29, 1995.

RADIN, B. et al. Eficiência de interceptação da radiação fotossinteticamente ativa pela cultura do tomateiro em diferentes ambientes. In: REUNION ARGENTINA DE Agrometeorologia, 9., 2002, Vaquerias. Anales... Cordoba: Universidade Nacional de Cordoba, 2002. CD Rom.

RIGHI, E.Z. Consumo hídrico do tomateiro (Lycopersicon esculentum Mill.) cultivado em estufa plástica e sua relação com variáveis meteorológicas em Santa Maria, RS. 2000. 83f. Dissertação (Mestrado em Agrometeorologia) - Programa de Pós-graduação em Física do Ambiente Agrícola, Escola Superior de Agricultura Luiz de Queiroz/Universidade de São Paulo. 
RITCHIE, J.T. Wheat phasic development. In: HANKS, R.J.; RITCHIE, J.T. Modeling plant and soil systems. Madison: ASA, CSSA, and SSSA, 1991. Cap.3, p.31-54.

RUSSELE, M.P. et al. Growth analysis based on degree days. Crop Science, v.24, n.1, p.28-32, 1984.

SAS Institute, Inc. SAS-S. Guide, Version 6.0. Cary, NC, 1997. 494p.

SCHUH, M. et al. Vernalização afeta o filocrono em lírio. Bragantia, v.64, n.1, p.25-32, 2005.

SHOLBERG, J. et al. Growth and canopy characteristics of field-grown tomato. Agronomy Journal, v.92, p.152-159, 2000.

SILVA, J.B.C. et al. Tomate para processamento industrial. Brasília: Embrapa Hortaliças, 2000. 168p.

SINCLAIR, T.R. et al. Sugarcane leaf area development under field conditions in Florida, USA. Field Grops Research, v.88, n.1, p.171-178, 2004.

STRECK, N.A. Generalized nonlinear air temperature response function for node appearance in muskmelon (Cucumis melo L.). Revista Brasileira de Agrometeorologia, v.10, n.1, p.105-111, 2002.

STRECK, N.A. et al. Incorporating a chronology response into the prediction of leaf appearance rate in winter wheat. Annals of Botany, v.92, p.181-190, 2003.

STRECK, N.A. et al. Estimating the phyllochron in lily (Lilium longiflorum Thumb.). Revista Brasileira de Agrometeorologia, v.12, n.2, p.355-358, 2004.
STRECK, N.A. et al. Estimativa do plastocrono em meloeiro (Cucumis melo L.) cultivado em estufa plástica em diferentes épocas do ano. Ciência Rural, v.35, n.6, p.1275-1280, 2005a.

STRECK, N.A. et al. Estimating leaf appearance and phyllochron in safflower (Carthamus tinctorius L.). Ciência Rural, v.35, n.6, p.1448-1450, 2005b.

VOS, J.; BIEMOND D.J. Effects of nitrogen on the development and growth of the potato plant. 1. Leaf appearance, expansion, growth, life spans of leaves and branching. Annals of Botany, v.70, n.1, p.27-35, 1992.

WALTER, L.C. et al. Filocrono de alguns genótipos brasileiros de arroz irrigado. In: CONGRESSO BRASILEIRO DE AGROMETEOROLOGIA, 14., 2005, Campinas, SP. Anais... Campinas: Sociedade Brasileira de Agrometeorologia, 2005. 173p. p.07.

WEIR, A.H. et al. A winter wheat crop simulation model without water or nutrients limitations. Journal of Agricultural Science, v.102, n.2, p.371-382, 1984.

WILHELM, W.W.; McMASTER, G.S. Importance of the phyllochron in studyng development and growth in grasses. Crop Science, v.35, n.1, p.1-3, 1995.

XUE, Q. et al. Predicting leaf appearance in field-grown winter wheat: evaluating linear and non-linear models. Ecological Modelling, v.175, p. 261-270, 2004. 